\title{
A Robust Model for Circadian Redox Oscillations
}

\author{
Marta del Olmo ${ }^{1, *(\mathbb{D}}$, Achim Kramer ${ }^{2}$ and Hanspeter Herzel ${ }^{1, *(\mathbb{D}}$ \\ 1 Institute for Theoretical Biology, Charité and Humboldt-Universität zu Berlin, 10115 Berlin, Germany \\ 2 Laboratory of Chronobiology, Charité-Universitätsmedizin Berlin, 10117 Berlin, Germany; \\ achim.kramer@charite.de \\ * Correspondence: marta.del-olmo@charite.de (M.d.O.); h.herzel@biologie.hu-berlin.de (H.H.)
}

Received: 26 March 2019; Accepted: 8 May 2019; Published: 13 May 2019

\begin{abstract}
The circadian clock is an endogenous oscillator that controls daily rhythms in metabolism, physiology, and behavior. Although the timekeeping components differ among species, a common design principle is a transcription-translation negative feedback loop. However, it is becoming clear that other mechanisms can contribute to the generation of $24 \mathrm{~h}$ rhythms. Peroxiredoxins (Prxs) exhibit $24 \mathrm{~h}$ rhythms in their redox state in all kingdoms of life. In mammalian adrenal gland, heart and brown adipose tissue, such rhythms are generated as a result of an inactivating hyperoxidation reaction that is reduced by coordinated import of sulfiredoxin (Srx) into the mitochondria. However, a quantitative description of the Prx/Srx oscillating system is still missing. We investigate the basic principles that generate mitochondrial Prx/Srx rhythms using computational modeling. We observe that the previously described delay in mitochondrial Srx import, in combination with an appropriate separation of fast and slow reactions, is sufficient to generate robust self-sustained relaxation-like oscillations. We find that our conceptual model can be regarded as a series of three consecutive phases and two temporal switches, highlighting the importance of delayed negative feedback and switches in the generation of oscillations.
\end{abstract}

Keywords: redox; oscillations; mathematical modeling; negative feedback; fast vs. slow reactions; phases; switches

\section{Introduction}

The Earth's regular $24 \mathrm{~h}$ rotation has led to the evolution of circadian oscillators in all kingdoms of life. These oscillations control daily rhythms in metabolism, physiology, and behavior, and they allow organisms to adapt their physiological needs to the time of day in an anticipatory fashion [1,2]. When the internal clocks run in synchrony with the external world, they provide organisms with significant competitive advantages [3].

Although the molecular clockwork components have widely divergent origins and are not conserved across the main divisions of life, a common design principle has been applied to all organisms where circadian timing mechanisms have been investigated. This paradigm relies on a negative transcription-translation feedback loop (TTFL), where protein products of clock genes feed back periodically to regulate their own expression and drive rhythmic output pathways and physiology $[2,4,5]$. Mounting evidence suggests that transcription-based oscillators are not the only means by which cells track time. Some examples of non-transcriptional oscillators are (i) the cyanobacterial phosphorylation oscillator, which can be reconstituted in vitro [6]; (ii) the circadian photosynthetic rhythms that persist in green algae after enucleation and hence in the absence of nuclear transcription [7]; or (iii) the peroxiredoxin oxidation rhythms found in red blood cells [8], which are anucleate.

Peroxiredoxins (Prx) are a conserved family of antioxidant enzymes that maintain the cellular redox state by clearing the cell from reactive oxygen species (ROS). They reduce hydrogen peroxide 
$\left(\mathrm{H}_{2} \mathrm{O}_{2}\right)$ to water with the use of reducing equivalents provided by other physiological thiols [9]. As a result ROS removal, Prxs become oxidized in their active site [9]. Interestingly, and in contrast to the divergent evolution of the TTFL, levels of oxidized Prx have been shown to oscillate with a circadian period in all kingdoms of life [10]. The exact mechanism that generates circadian Prx redox rhythms, however, still remains an open question, and it seems to be different in different cell types (Figure 1A). Sulfiredoxin (Srx), the enzyme that reduces oxidized Prx, is likely a key determinant of Prx3 hyperoxidation rhythms in mammalian adrenal gland, heart, and brown adipose tissue [11]. In red blood cells from Srx knockout mice, however, Prx redox oscillations persist, and rhythms have been shown to be dependent on the degradation of the oxidized enzyme by the proteasome [12]. Moreover, the presence of Prx oscillations in organisms that lack Srx homologs such as C. elegans or $N$. crassa indicates that Prx reduction is, at least in some cases, dispensable for the cycle to occur.

A

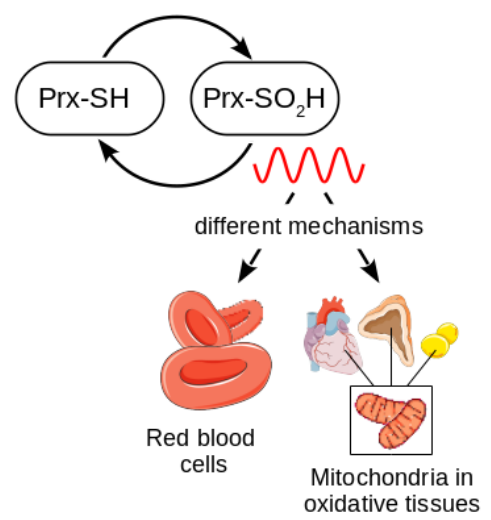

B

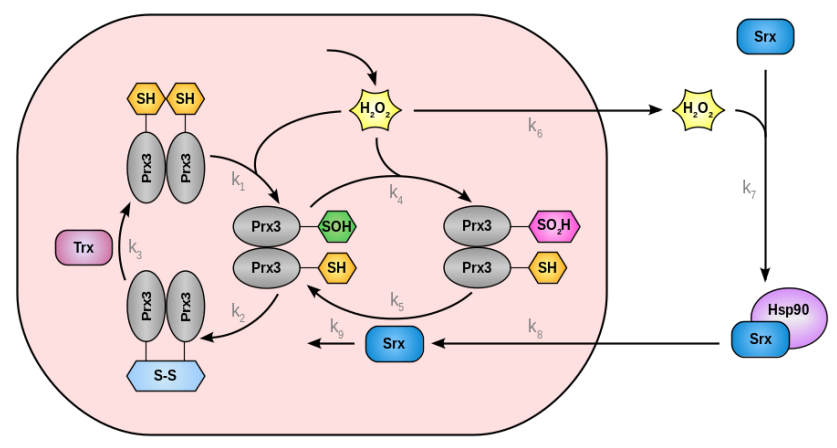

Figure 1. Peroxiredoxin (Prx) oxidation cycles occur with circadian periodicity in all kingdoms of life. (A) The mechanisms for $24 \mathrm{~h}$ rhythm generation in Prx hyperoxidation in mammals differ in different cell types. (B) Model for the mechanism underlying circadian oscillation of $\operatorname{Prx} 3-\mathrm{SO}_{2} \mathrm{H}$ and sulfiredoxin (Srx) levels in mitochondria of adrenal gland, heart, and brown adipose tissue. See text for details.

In this study, we use mathematical modeling to investigate the principles for Prx/Srx oscillations. Our results show that the combination of a fast Prx hyperoxidation event followed by a slow and delayed negative feedback loop is the minimal backbone that is required for the system to oscillate. We also find that this minimal motif produces relaxation-like oscillations with two temporal switch-like events, highlighting the importance of switches in the generation of oscillations.

\section{Results}

\subsection{Derivation of a Kinetic Model for Circadian Redox Oscillations}

Because of their potential to oxidize and damage cellular protein and lipids, ROS levels must be under tight regulation. Prx3 is one of the major antioxidant proteins involved in $\mathrm{H}_{2} \mathrm{O}_{2}$ removal in mitochondria. A conserved cysteine (Cys) residue in its active site is oxidized by $\mathrm{H}_{2} \mathrm{O}_{2}$ to Cys-sulfenic acid (Prx3-SOH, reaction $k_{1}$ in Figure 1B). This intermediate can react with a second conserved Cys from another Prx3 subunit to produce an intermolecular disulfide bond (reaction $k_{2}$ ), which can be reduced by the thioredoxin (Trx) system of the cell (reaction $k_{3}$ ). Alternatively, Prx3-SOH can undergo further oxidation, termed hyperoxidation, in an S-sulfinylation reaction, to form a sulfinic acid $\left(\operatorname{Prx} 3-\mathrm{SO}_{2} \mathrm{H}\right.$, reaction $\left.k_{4}\right)[9,13]$. Prx3- $\mathrm{SO}_{2} \mathrm{H}$ is catalytically inactive $[9,13]$, and in adrenal gland cells, brown adipocytes or cardiomyocytes, it can be reduced back to Prx3-SOH by action of sulfiredoxin (Srx) (reaction $k_{5}$ ) [11]. In other cell types and other model organisms, the Srx-mediated reduction of $\operatorname{Prx}-\mathrm{SO}_{2} \mathrm{H}$ is not required for rhythm generation [12].

In mitochondria from brown adipose, adrenal gland and heart tissue, $\mathrm{Prx} 3-\mathrm{SO}_{2} \mathrm{H}$ and Srx levels oscillate with a circadian period [11]. $\mathrm{H}_{2} \mathrm{O}_{2}$ increase results in the oxidation and inactivation of Prx3 (reactions $k_{1}$ and $k_{4}$ from Figure 1B). The consequence is the accumulation of $\mathrm{H}_{2} \mathrm{O}_{2}$ inside mitochondria 
and its overflow to the cytosol ( $k_{6}$ in Figure 1B). Cytosolic $\mathrm{H}_{2} \mathrm{O}_{2}$ activates pathways to control its own production. Among others, it stimulates Srx oxidation and intermolecular disulfide bridge formation with Hsp90 (reaction $k_{7}$ ) to promote translocation of Srx to the mitochondria (reaction $k_{8}$ ). Mitochondrial Srx can reduce and thus reactivate Prx3- $\mathrm{SO}_{2} \mathrm{H}$ (reaction $k_{5}$ ) [11]. Srx levels peak in mitochondria $\sim 8 \mathrm{~h}$ after $\operatorname{Pr} x 3-\mathrm{SO}_{2} \mathrm{H}$, and Srx becomes sensitive to degradation (reaction $k_{9}$ ) when Prx3- $\mathrm{SO}_{2} \mathrm{H}$ levels decrease [11]. The mitochondrial import of Srx thus constitutes a negative feedback that enables a new cycle of $\mathrm{H}_{2} \mathrm{O}_{2}$ removal and Prx3-SO ${ }_{2} \mathrm{H}$ accumulation (Figure 1B).

In order to understand how fast biochemical redox reactions result in slow $24 \mathrm{~h}$ rhythms, we develop a deterministic model containing the biochemical species from the Prx3/Srx system shown in Figure 1B. The complete set of equations of this large model, which we refer to as detailed model, are found in Appendix A. Unfortunately, quantitative details of the kinetic processes are not known and thus estimating parameters in such a large model represents a challenge. For this reason, and in order to gain insight into the design principles of redox rhythms in the Prx3/Srx system, we simplify the detailed model to its core motif (Figure 2A). Details of the model reduction are found in Appendix B.

A

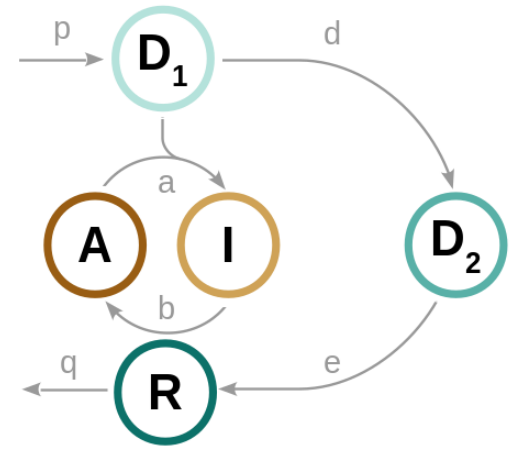

B

$$
\begin{aligned}
\frac{d D_{1}}{d t} & =p-a D_{1} \frac{b R}{b R+a D_{1}}-d D_{1}, \\
\frac{d D_{2}}{d t} & =d D_{1}-e D_{2}, \\
\frac{d R}{d t} & =e D_{2}-q R, \\
A & =\frac{b R}{b R+a D_{1}}, \\
I & =1-A=\frac{a D_{1}}{b R+a D_{1}} .
\end{aligned}
$$

Figure 2. Core model for redox circadian oscillations. Scheme $(\mathbf{A})$ and equations $(\mathbf{B})$ of the core redox oscillator model. A represents active peroxiredoxin 3 (Prx3-SOH); I, inactive Prx3 (Prx3-SO $\mathrm{SH}_{2}$; $D_{1}$, mitochondrial $\mathrm{H}_{2} \mathrm{O}_{2} ; D_{2}$, cytosolic $\mathrm{H}_{2} \mathrm{O}_{2}$; and $R$, mitochondrial Srx.

\subsection{A Low Dimensional Model Represents the Core Prx3-SO ${ }_{2} \mathrm{H} / \mathrm{Srx}$ Circadian Oscillator}

We identify the core motif that is required for generation of $\mathrm{Prx}_{3}-\mathrm{SO}_{2} \mathrm{H}$ and mitochondrial Srx circadian oscillations by systematically changing parameters and clamping variables to their mean value [14] (Appendix B). The scheme and equations of this minimal model are shown in Figure 2. It only contains the variables, kinetic parameters, and reactions that are necessary and sufficient for self-sustained rhythm generation.

The core oscillator model consists of only five variables and just one oxidation event (Figure 2A). $A$ represents the active but partially oxidized $\operatorname{Prx} 3(\mathrm{Prx} 3-\mathrm{SOH})$ that gets further hyperoxidized by the danger $1\left(D_{1}\right.$, mitochondrial $\left.\mathrm{H}_{2} \mathrm{O}_{2}\right)$ to produce the inactive $\operatorname{Prx} 3-\mathrm{SO}_{2} \mathrm{H}, I$. As the $A \rightarrow I$ reaction occurs, $A$ levels decrease. The result is that the ability of mitochondria to remove $D_{1}$ also decreases. When mitochondria can no longer eliminate the oxidant, $D_{1}$ accumulates and overflows to the cytosol, where it is referred to as danger $2\left(D_{2}\right.$, cytosolic $\left.\mathrm{H}_{2} \mathrm{O}_{2}\right) . D_{2}$ activates the translocation of the rescuer $R$ (mitochondrial Srx), that reduces $I$ back to $A$, closing the negative feedback loop. The Prx3-SH oxidation to Prx3-SOH and the $D_{2}$-induced oxidation of cytosolic Srx (reactions $k_{1}$ and $k_{7}$ in Figure 1B) were found to be dispensable for rhythm generation. Thus, these biochemical species, as well as the reactions they take part in, are omitted from the minimal model.

We formulate ordinary differential equations (ODEs) to describe the behavior of the system over time. Production and removal terms are modeled with mass action kinetics (Figure 2B). The nonlinear term in the model arises from the quasi-steady state approximation $[15,16]$ performed on the equation for variable $A$, whose production and removal reactions are modeled as bilinear terms (details provided in Appendix B). We assume constant $D_{1}$ production (parameter $p$ in the model) and constant 
Prx3 pool $A+I$ over time. Moreover, we only consider the negative feedback performed by $R$-induced reactivation of $A$, which is stimulated by the $D_{2}$ increase. However, other additional feedback loops might exist, as seen by studies that have shown that cytosolic $\mathrm{H}_{2} \mathrm{O}_{2} D_{2}$ can feed back and decrease $D_{1}$ production by activation of the stress-activated protein kinase p38 MAPK, among other pathways [17].

\subsection{Design Principles of the Redox Oscillator: Fast A Inactivation Followed by a Slow Negative Feedback Loop}

The dynamics of a system depend greatly on parameter values. Unfortunately, most kinetic rates in the Prx3/Srx sytem are not known in quantitative detail and therefore finding reasonable parameters represents a major challenge. Nevertheless, some physiological constraints can be taken into account to narrow down the plausible range of parameter values. First of all, the system needs to oscillate with a circadian period and the phase relationship between $I$ and $R$ should be approximately $8 \mathrm{~h}$, according to previously published data [11]. Other constraints come from enzymatic assays performed with Prx3 and Srx, as well as from studies that have focused on $\mathrm{H}_{2} \mathrm{O}_{2}$ signaling and transport [11,18-24]. They have estimated rates of Prx3 hyperoxidation, Srx-mediated $\mathrm{Prx} 3-\mathrm{SO}_{2} \mathrm{H}$ reduction, and Srx degradation and have allowed the derivation of a reasonable rate for $\mathrm{H}_{2} \mathrm{O}_{2}$ translocation across membranes (Table 1).

Table 1. Physiological parameter constraints that allow finding plausible parameter ranges in the peroxiredoxin ( $\operatorname{Prx}$ ) 3/sulfiredoxin (Srx) oscillating system. The rates of Prx3 hyperoxidation (I formation), Srx-mediated Prx3 reduction (rescue of $A$ ), and Srx degradation ( $R$ removal) have been determined by enzymatic assays in previous studies. The rate of mitochondrial $\mathrm{H}_{2} \mathrm{O}_{2}$ translocation ${ }^{*}$ is estimated from experimental and theoretical studies that have focused on $\mathrm{H}_{2} \mathrm{O}_{2}$ transport and signaling.

\begin{tabular}{cccc}
\hline Model Parameter & Reaction Rate & Physiological Values & References \\
\hline$p$ & mitochondrial $\mathrm{H}_{2} \mathrm{O}_{2}$ production & - & - \\
$a$ & Prx3-SOH hyperoxidation (and Prx3 inactivation) & $10^{4} \mathrm{M}^{-1} \mathrm{~s}^{-1}$ & {$[18]$} \\
$b$ & Prx3-SO $\mathrm{S}_{2} \mathrm{H}$ reduction (and Prx3 reactivation) & $2 \mathrm{M}^{-1} \mathrm{~s}^{-1}$ & {$[19]$} \\
$d$ & $\mathrm{H}_{2} \mathrm{O}_{2}$ translocation to cytosol & $1 \mathrm{~s}^{-1}$ & {$[20-23]$} \\
$e$ & $\mathrm{~S} x$ translocation to mitochondria & - & - \\
$q$ & mitochondrial Srx degradation & $0.16 \mathrm{~h}^{-1}$ & {$[11,24]$} \\
\hline
\end{tabular}

${ }^{*} \mathrm{H}_{2} \mathrm{O}_{2}$ transport through biological membranes is thought to occur via aquaporins (Aqp) [20]. The typical diameter of an aquaporin is $\sim 20 \AA$ [21] and biological membranes typically contain $30 \mathrm{Aqp} / \mu \mathrm{m}^{2}$ [22] (although this number might vary across cell and membrane types). Thus, the total Aqp area that can transport $\mathrm{H}_{2} \mathrm{O}_{2}$ out of the mitochondria is $\sim 100 \mathrm{~nm}^{2}$ per $\mu m^{2}$ of membrane. In other words, $0.01 \%$ of the membrane area contains Aqp. Very generally, the probability of an $\mathrm{H}_{2} \mathrm{O}_{2}$ molecule to diffuse can be assumed to be in the same order of magnitude of its probability to get reduced by Prxs [23]. With the limitation that only $0.01 \%$ of the membrane allows $\mathrm{H}_{2} \mathrm{O}_{2}$ translocation, the probability of $\mathrm{H}_{2} \mathrm{O}_{2}$ being transported out of the mitochondria is $0.01 \%$ of its probability of getting reduced, i.e., 10,000 -fold lower than its reduction rate $a$.

In order to obtain a reasonable set of parameters that satisfies the physiological constraints, we systematically vary all model parameters and perform bifurcation and sensitivity analyses. Bifurcation diagrams show under which parameter values the system oscillates and sensitivity analyses address how the oscillation period varies over the oscillatory range as a parameter is changed.

Bifurcation diagrams are presented for a selected choice of parameters in Figure $3 \mathrm{~A}-\mathrm{C}$. The bifurcation plots show that the system oscillates for values of $d, e, q<1$. The limit cycle emerges at $d=0.02$ and disappears at $d=0.5$ (Figure 3A, bifurcation plots for parameters $e$ and $q$ are shown in Appendix C). We also find that, in contrast to small $d, e, q$ parameter values, the system requires a 1000-10,000-fold higher $a$ oxidation rate to enter into the oscillatory regime. The Hopf bifurcation occurs at $a=120$ (Figure 3B) and once this value is reached, oscillations persist for a wide range of kinetic parameters, with little effects in oscillation amplitude or period, indicating robustness of the model. The period sensitivity analyses reveal that the oscillation period depends strongly on the translocation rates $d$ and $e$ and on the $R$ degradation parameter $q$, being most sensitive to changes in parameter $d$ (Figure $3 \mathrm{C}$ and Appendix D). 
A

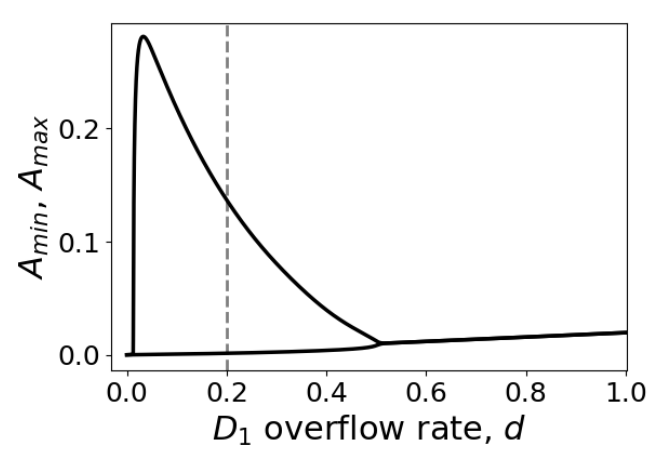

C

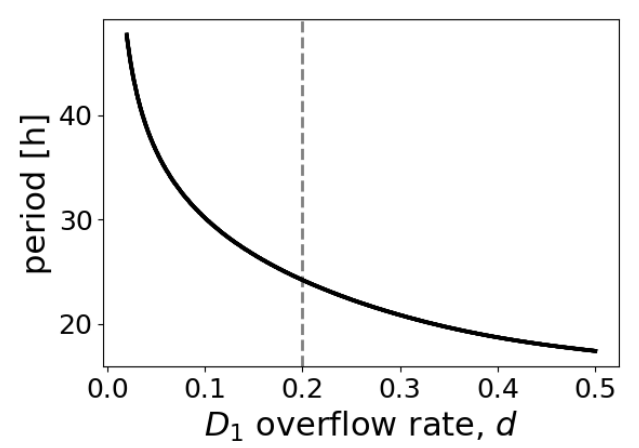

B

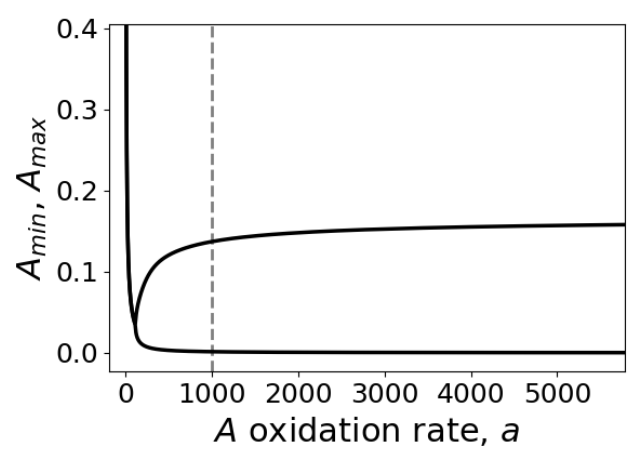

D

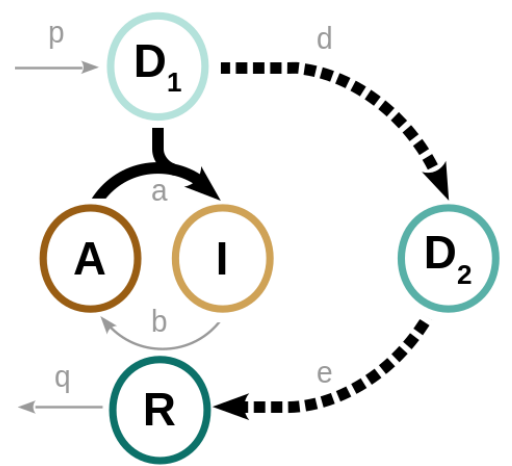

Figure 3. Fast $A$ inactivation followed by a slow negative feedback loop is the design principle of the Prx3/Srx redox oscillator. Bifurcation diagrams as a function of the model parameters $d(\mathbf{A})$ and $a(\mathbf{B})$. At $d=0.02$ and $a=120$ self-sustained oscillations emerge. $A_{\min }$ and $A_{\max }$ represent the minimum and maximum values of $A$ in the oscillatory regime. (C) Variation of period as a function of $d$. The curves shown in panels (A-C) are obtained for the default parameter set given in the caption of Figure 4 . The dashed gray lines depict the default parameter values given in the caption of Figure 4 . (D) Sketch of the core backbone for $I / R$ redox oscillations: fast $D_{1}$-induced $A$ inactivation (continuous thick line) followed by a slow $D_{1}-D_{2}-R$ negative feedback loop (dashed line).

These findings show that a fast $A$ inactivation reaction (high $a$ value) in combination with a slower negative feedback loop (1000-10,000-fold lower $d, e, q$ rates) constitute the backbone of the redox oscillator model (Figure 3D). We thus find a plausible set of model parameter values that produce robust circadian oscillations with the expected characteristics: a period of $24.2 \mathrm{~h}$ and a $I / R$ phase difference of $8.7 \mathrm{~h}$, as determined by maxima estimation of the $R$ and $I$ dynamics (Figure 4). Moreover, the parameter choice is in agreement with the high Prx3 oxidation rate measured experimentally [18] and with the $\sim 10,000$-fold slower physiological $\mathrm{H}_{2} \mathrm{O}_{2}$ translocation (Table 1).

According to our results, only a small fraction of active Prx $3 A$ is needed to keep $D_{1}$ levels close to 0 , as seen by the higher $I$ levels compared to $A$ during the whole simulated time (Figure 4). The results also predict that $D_{2}$ levels peak $3.9 \mathrm{~h}$ after $D_{1}$ (or $4.5 \mathrm{~h}$ after $I$ ), an observation that could be relevant in the context of the canonical TTFL and will be further addressed in the Discussion section. 


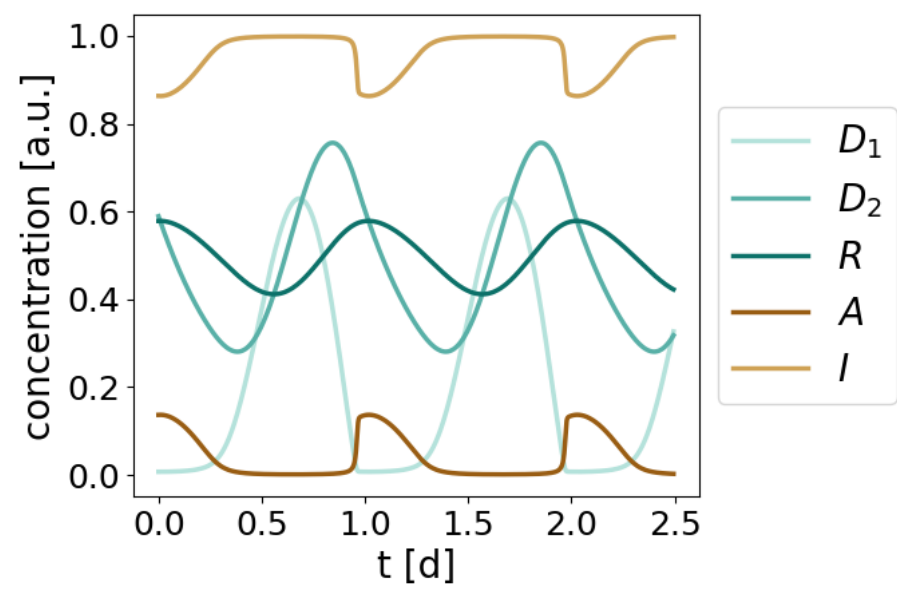

Figure 4. Dynamics of the redox model. Limit cycle oscillations obtained by numerical integration of the equations shown in Figure 2B for the following parameter values (arbitrary units, a.u.): $p=1, a=$ $1000, b=2, d=0.2, e=q=0.1$. Consistent with experimental data [11] and with the model constraints (Table 1), the resulting period is $24.2 \mathrm{~h}$ and the phase shift between $I$ and $R$ is $8.7 \mathrm{~h}$.

Interestingly, insights from the redox oscillator model apply as well to larger and more complex models. Firstly, negative feedback loops $\left(D_{1}-D_{2}-R\right.$ in the minimal model) as well as nonlinear terms (given by the $A$ equation, Figure 2B) are required to achieve self-sustained oscillations [25]. Secondly, overcritical delays about quarter to half of a period are necessary for oscillations to arise [25-27] (in the minimal model, slow $d, e, q$ rates are required to yield the $8.7 \mathrm{~h}$ delay). Lastly, translocation and degradation rates have profound effects on the period [28-31]. It should be noted, nevertheless, that the choice of parameters is not tailored to specific kinetic data. Kinetic parameters might differ among tissues and might also depend on physiological conditions.

\subsection{The I/R Redox Oscillator is Characterized by Three Phases and Two Temporal Switches}

We have shown that, in order to oscillate, the mitochondrial $\operatorname{Prx}_{-}-\mathrm{SO}_{2} \mathrm{H} / \mathrm{Srx}(I / R)$ system requires a fast $D_{1}$-induced inactivation of $A$ followed by a lengthy and slower negative feedback loop $D_{1}-$ $D_{2}-R$ that reactivates $A$ (Figure 3D). As seen by the equations from Figure 2B, the dynamics of $A, I$, and $D_{1}$ depend on the fast $a$ oxidation rate compared to the slower dynamics of $D_{2}$ or $R$. This is reflected in the relaxation- or triangular-like waveforms of $A, I$, and $D_{1}$ (Figure 4). Such relaxation oscillations are generally characterized by two consecutive processes that occur on different timescales. There are intervals of time, during which little happens ( $A=0$ or $I=1$ in the system's dynamics), followed by time intervals with considerable changes. The result is the triangular-like dynamics observed for $A, I$, and $D_{1}$ (Figure 4).

It is known that oscillations depend on negative feedbacks, but that in the absence of appropriate delays or nonlinear terms, negative feedback circuits often settle into a stable steady state termed homeostasis $[25,32,33]$. Several computational studies have demonstrated that sufficiently strong nonlinearities are required to generate self-sustained oscillations [31,34-36]. Such nonlinear terms often exhibit sigmoidal or switch-like characteristics. Surprisingly, no switch-like curve is evident from the only nonlinear term of the model $a b \frac{D_{1} R}{b R+a D_{1}}$ (Figure 2B and Appendix B), nor from the response of any variable to upstream components (data not shown). Nonetheless, we find that this term is at the core of the oscillations, as its linearization results in the stabilization of the steady state. The large value of $a$ allows the production of self-sustained rhythms, even in the absence of an explicit kinetic switch.

In order to emphasize the importance of the nonlinear term in the context of oscillations, and given the switch-like dynamics of $A, I$, and $D_{1}$, we still use the term switch. Instead of using it to describe how the steady state of a first component responds to a second component which is upstream of the 
former (often done in the literature [36-39]), we focus here on temporal switches that mark transitions between phases. We see that the model dynamics can be split into three phases separated by two temporal switches (Figure 5).

A

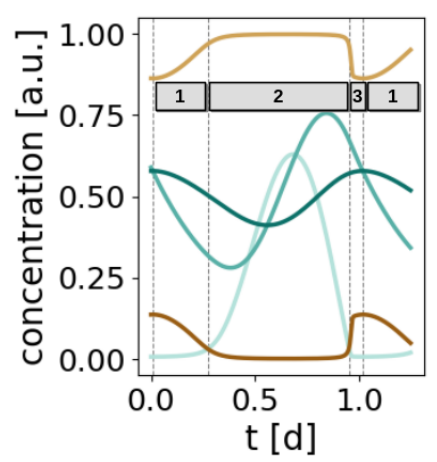

B

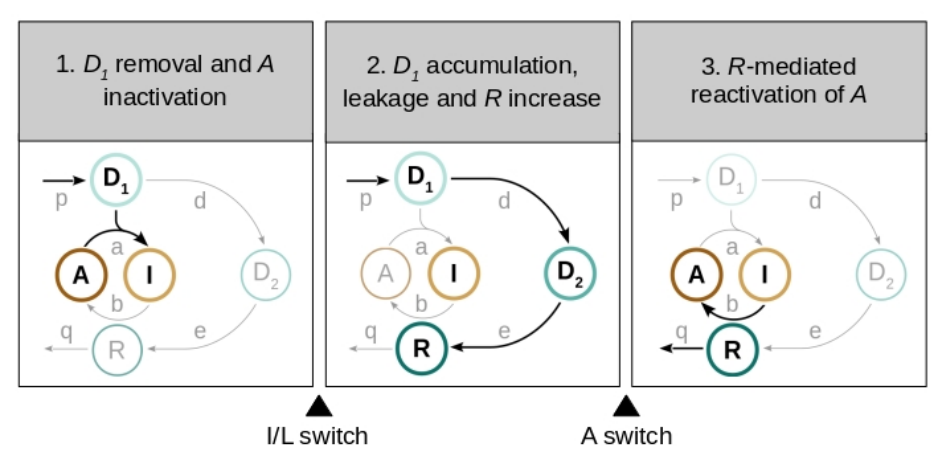

Figure 5. A series of three phases and two temporal switches can be regarded as the mechanism for generation of redox oscillations. (A) Division of the temporal dynamics of the $I / R$ system into three phases that explain the major transitions of the model components. (B) Scheme of the major events that take place in each phase (see main text for details).

The first phase is characterized by the inactivation of $A$ as a result of $D_{1}$ removal. As long as there is active $\operatorname{Prx} 3(A)$ in the system, mitochondrial $\mathrm{H}_{2} \mathrm{O}_{2}\left(D_{1}\right)$ levels are kept in check and $D_{1}$ is removed. But the cost of the $D_{1}$ clearance is the inactivation of $A$ to $I$, and thus $A$ levels decrease as $I$ increases (first box in Figure $5 \mathrm{~B}$ ). When most of the active Prx3 pool $A$ has been hyperoxidized and inactivated to $I$, the first switch occurs and the system progresses to the next phase. As a consequence of the $A$ inactivation, its ability to remove $D_{1}$ molecules decreases and thus $D_{1}$ accumulates and leaks to the cytosol. In other words, the flux of $D_{1}$ changes from inactivating $A$ to leaking, what gives this first temporal switch its name: inactivation/leakage (I/L) switch. As a result of the I/L switch, $D_{1}$ accumulates, leaks and activates the $D_{1}-D_{2}-R$ negative feedback. Consequently, $D_{2}$ and $R$ levels increase (phase 2, second box in Figure 5B). At the end of the second phase, the increase in $R$ is accompanied by a decrease in $D_{1}$. Once $D_{1}$ and $R$ reach critical values in the nonlinear term, the negative feedback becomes effective and the dynamics of $A$, that are governed by the nonlinearity (Figure 2B), change suddenly. This triggers the activation (A) switch and the sharp increase in $A$ levels (phase 3, third box in Figure 5B). The system is thus switched to its active state and a new round of $D_{1}$ removal can start. Furthermore, $R$ becomes sensitive to degradation. The series of two temporal switches separate the two timescales in the relaxation oscillations. The I/L switch sets the start of the slow timescale (the negative feedback loop), whereas the A switch marks the beginning of the fast clearance of $D_{1}$.

\section{Discussion}

\subsection{A Novel Circadian Redox Oscillator Model}

We have designed the first model for the complex biochemical system of Prx3- $\mathrm{SO}_{2} \mathrm{H} / \mathrm{Srx}$ redox oscillations and we find that the loop Prx3-SOH - Prx3- $\mathrm{SO}_{2} \mathrm{H}$, together with the negative feedback mediated by Srx (Figure 1B), is necessary and sufficient for the generation of oscillations. The design principles of this oscillator are (i) a fast Prx3-SOH inactivation followed by (ii) a slow and delayed negative feedback loop, where mitochondrial $\mathrm{H}_{2} \mathrm{O}_{2}$ leaks to the cytosol to promote the translocation of cytosolic Srx to mitochondria, approximately $9 \mathrm{~h}$ after the inactivation of Prx3-SOH. This simple backbone reproduces the previously described circadian oscillations of mitochondrial $\mathrm{Prx}_{3}-\mathrm{SO}_{2} \mathrm{H}$ and Srx as well as the delay in mitochondrial Srx import. 
Although quantitative details of the kinetic parameters in the Prx3/Srx system remain largely unknown, we have found a reasonable set of parameters that is consistent with the biology they describe. Previous biochemical studies have estimated that Prxs are 1000-10,000 times more reactive to $\mathrm{H}_{2} \mathrm{O}_{2}$ than other reduced cellular thiols [18], and that thus they can confine the diffusion of the oxidant [23]. Under the assumption that $0.01 \%$ of the membrane area contains transport proteins (Aqp) that can passively transport $\mathrm{H}_{2} \mathrm{O}_{2}$ out of the compartment [22], the translocation rate of $\mathrm{H}_{2} \mathrm{O}_{2}$ is 10,000-fold smaller than its reduction rate (Table 1). This is in agreement with the parameter values, $a=1000$ and $d=0.2$. Since the import of Srx to mitochondria also requires a protein transporter, we have assumed this rate to be in the same order of magnitude as the translocation of $\mathrm{H}_{2} \mathrm{O}_{2}$ to the cytosol. The experimental determination of the rate at which a protein is transported through a membrane is challenging, because the transport depends on a number of factors including $\mathrm{pH}$, membrane voltage, protein length, protein $3 \mathrm{D}$ conformation, membrane fatty acid composition, and ATP levels (if the transport is active), among others. Hence the estimation of translocation kinetics is only preliminary. Furthermore, the choices for Srx degradation rate $q$ and hyperoxidized Prx3 reduction rate by Srx $b$ are consistent with previous experimental studies, which have estimated a half-life of sulfiredoxin of $4-5 \mathrm{~h}[11,24]$, and a rate of reduction of hyperoxidized Prx by Srx of approximately $2 \mathrm{M}^{-1} \mathrm{~s}^{-1}$, 1000-10,000 times smaller than its oxidation rate [19] (Table 1).

It is known that relaxation oscillations typically depend on positive feedback loops $[40,41]$. However, even in the absence of explicit positive feedback loops, the redox oscillator model still produces oscillations of Prx3-SOH, Prx3-SO $\mathrm{SO}_{2} \mathrm{H}$ and mitochondrial $\mathrm{H}_{2} \mathrm{O}_{2}$ that are of relaxation type. Two temporal switches characterize their triangular-like waveform and divide the system's dynamics into three phases. A summary is shown in Figure 6. This scheme with three phases and two switches is reminiscent to that of the cell cycle. A series of biochemical switches controls transitions between the various phases of the cell cycle. They maintain its orderly progression and act as checkpoints to ensure that each phase has been properly completed before progression to the next phase. Such switches have been shown to generate decisive, robust (and potentially irreversible) transitions and trigger stable oscillations $[33,42,43]$. It should be noted, however, that the switches that regulate cell cycle transitions are the consequence of a complicated network of positive and negative feedback loops and result in bistability, as opposed to our simple model that (strikingly) contains only one negative feedback loop. The redox model highlights the importance of negative feedbacks and the diversity of switches in the context of oscillations.

The detailed model (Appendix A) also oscillates along the lines of the design principles identified for the reduced model. It shows the same characteristics: relaxation oscillations, temporal switches, and expected period and $I / R$ phase delay, supporting the robustness of the minimal core model. According to biochemical assays, the rate constant for Prx3-SH oxidation to sulfenic acid Prx3-SOH is in the order of $10^{7} \mathrm{M}^{-1} \mathrm{~s}^{-1}$ [18]. From the simulations of the detailed model we see that when this rate $\left(k_{1}\right.$ in the model) increases, the amplitude of $\mathrm{Prx} 3-\mathrm{SO}_{2} \mathrm{H}$ and $\mathrm{Srx}$ oscillations also increases (Appendix A). This suggests that although the loop Prx3-SH - Prx3-SOH - Prx3-SS - Prx3-SH is not required for oscillations, it fine-tunes the dynamics of the Prx3/Srx oscillatory system. Large Prx3- $\mathrm{SO}_{2} \mathrm{H}$ and $\mathrm{Srx}$ amplitudes are in agreement with experimental data. Western blots show intense bands at the peak of Prx3- $\mathrm{SO}_{2} \mathrm{H}$ or Srx oscillations and no bands at the trough [11]. 


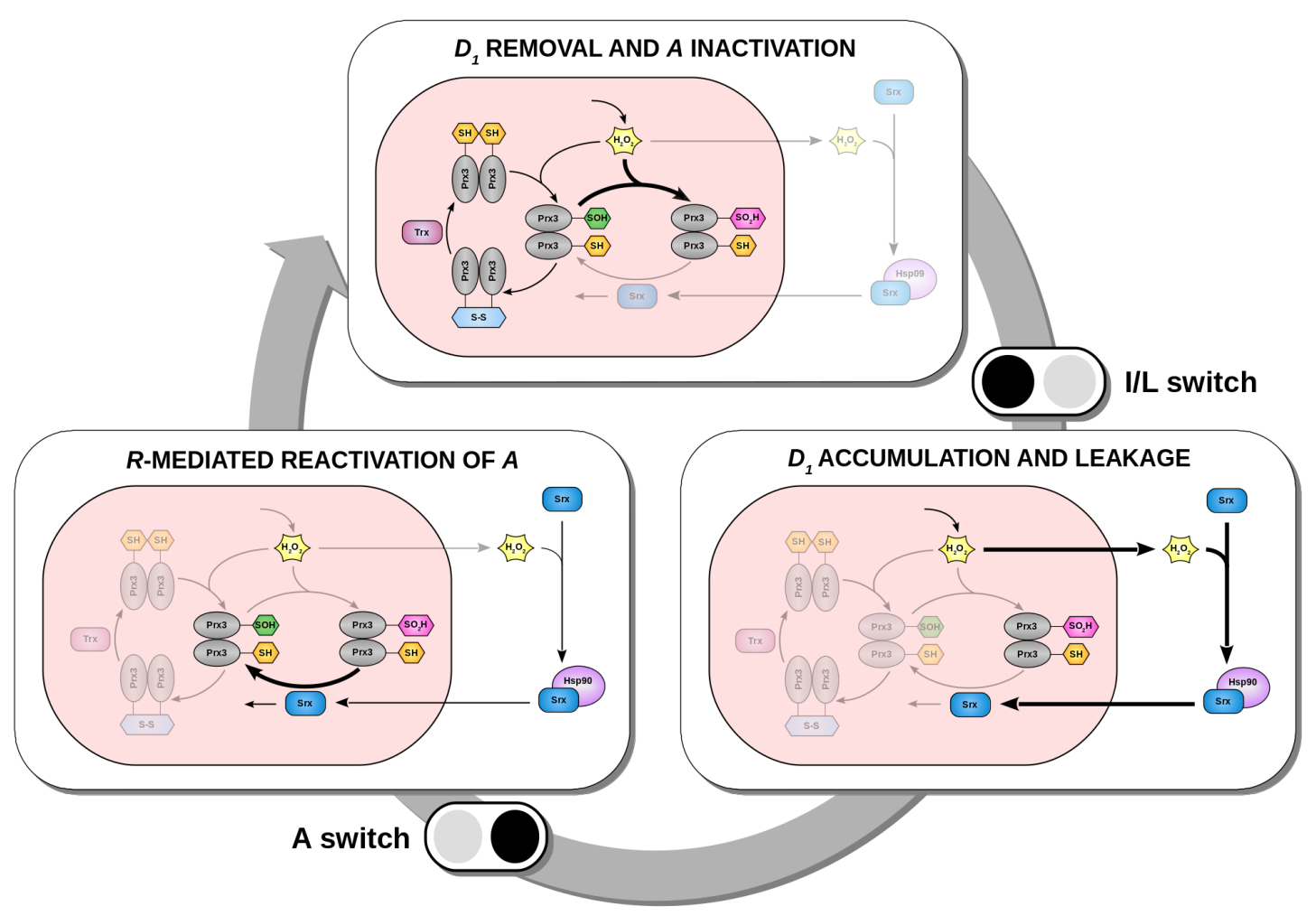

Figure 6. Model for the mechanism underlying circadian oscillations of $\operatorname{Prx} 3-\mathrm{SO}_{2} \mathrm{H}$ and Srx in mitochondria of mammalian adrenal gland, heart, and brown adipose tissue. Three phases and two temporal switches conceptually explain the generation of oscillations. The switches are represented by the black/gray icons. The switch occurs from black to gray: the black circle represents the phase from which the system comes, and the gray circle depicts the phase it progresses to.

\subsection{Alternative Views on the Nature of the Negative Feedback in the Redox Oscillator}

The oscillator model presented here applies to Prx oscillations in mammalian adrenal gland, heart, and brown adipose tissue. Prx daily rhythms have been found not only in mammals, but also in a variety of eukaryotes, cyanobacteria, and archaea, making these oscillation an evolutionarily conserved circadian rhythm marker [10]. A key unanswered question is what determines Prx oscillations in other cell types and phyla. Srx indeed accounts for the oscillations in adrenal gland, brown adipose tissue, and heart [11], but other organisms that display oscillations in Prx do not express Srx homologs (e.g., C. elegans and N. crassa), suggesting that other mechanisms might be in place. The same is true for mouse red blood cells. Although they express Srx, Prx- $\mathrm{SO}_{2} \mathrm{H}$ rhythms are largely unaltered in erythrocytes derived from Srx knockout mice and, by contrast, application of proteasome inhibitors eliminated the decay phase of the Prx-SO $\mathrm{S}_{2} \mathrm{H}$ rhythm in wild-type mouse erithrocytes [12]. These findings suggest that proteasomal degradation might account for the decay phase and hence for the negative feedback of the Prx-SO $\mathrm{S}_{2} \mathrm{H}$ oscillations in other cell types and phyla.

\subsection{Crosstalk between Prx Rhythms and the TTFL in Eukaryotic Organisms}

Given that Prx proteins and their oxidation rhythms are highly conserved among species, Prx rhythms seem to be evolutionarily ancient. It is also likely that they emerged before the circadian TTFL, which is believed to have evolved independently in separate species [10]. It is an important goal to now understand the relationship between the canonical TTFL and Prx oscillations, as it is becoming evident that there is a reciprocal interplay between the two. In one direction, the period length of $\mathrm{Prx}-\mathrm{SO}_{2} \mathrm{H}$ rhythms is extended in embryonic fibroblasts derived from $\mathrm{Cry} 1 / 2^{-/-}$mice [8]. In behaviorally arhythmic Drosophila mutants and N. crassa mutants displaying a lengthened period, 
Prx oscillations are perturbed in phase [10]. In the other direction, Arabidopsis mutants lacking Prx genes display TTFL rhythms that are altered in phase or amplitude [10], and knockdown of specific PRX isoforms in human U2OS cells affects the period length and amplitude of clock gene rhythms [44].

The modeling approach described in this study assumes constant $\mathrm{H}_{2} \mathrm{O}_{2}$ production. Nevertheless, the sources of mitochondrial $\mathrm{H}_{2} \mathrm{O}_{2}$ in tissues where the redox clockwork is present have been shown to be, at least in part, under the control of the circadian TTFL. In adrenal gland, for example, the major source of $\mathrm{H}_{2} \mathrm{O}_{2}$ is steroidogenesis, and this process is regulated by the TTFL [45,46]. In heart or brown adipose tissue, in which oxidative metabolism is very high, the respiratory component becomes an important source of $\mathrm{H}_{2} \mathrm{O}_{2}$, and respiration rate has also been shown to be rhythmically controlled by the canonical TTFL [47].

Moreover, the Prx3/Srx redox oscillator model contains only one negative feedback, namely the reduction of $\operatorname{Prx} 3-\mathrm{SO}_{2} \mathrm{H}(I)$ by $\mathrm{Srx}(R)$, which is stimulated by the cytosolic $\mathrm{H}_{2} \mathrm{O}_{2}\left(D_{2}\right)$ increase. Cytosolic $\mathrm{H}_{2} \mathrm{O}_{2}$, however, can signal as a second messenger and activate the p38 MAPK pathway to decrease mitochondrial $\mathrm{H}_{2} \mathrm{O}_{2}$ production [11,17]. The periodic $\mathrm{H}_{2} \mathrm{O}_{2}$ release to the cytosol is expected to act on other cytosolic or nuclear targets that are not yet identified. Canonical clock proteins might be directly or indirectly affected by the cytosolic $\mathrm{H}_{2} \mathrm{O}_{2}$ increase. This idea is supported by a study from 2014, which showed that the interaction of the two mammalian core clock proteins PER2 and CRY1 is redox-sensitive [48], as well as by other studies that have shown that the cellular redox poise can regulate the TTFL oscillator $[49,50]$. The $\mathrm{H}_{2} \mathrm{O}_{2}$ leakage might thus represent a potential coupling node between both the redox and the TTFL clock. The reciprocal interplay between the Prx system and the local TTFL clock might allow synchronization between local metabolic activity and systemic circadian regulation. The presence of Srx as part of the Prx clockwork in adrenal gland, brown adipose tissue or heart, but not in the liver, for instance, might indicate differences in how metabolic signals are transmitted to the TTFL.

\subsection{Model Predictions}

Mathematical models are most useful when they make predictions that can be tested (and hopefully validated) in vivo. Because the Prx3/Srx oscillator model is not quantitative in detail due to the limited knowledge of rate constants, it only allows us to make some basic predictions. Interfering with the expression of Srx or specific aquoporin (Aqp) isoforms involved in the $\mathrm{H}_{2} \mathrm{O}_{2}$ translocation across mitochondrial membranes would, intuitively, disrupt Prx3/Srx oscillations. Moreover, the simulations show that $\mathrm{H}_{2} \mathrm{O}_{2}$ peaks in the cytoplasm $\sim 4.5 \mathrm{~h}$ after the peak of $\operatorname{Prx} 3-\mathrm{SO}_{2} \mathrm{H}$ (or $\sim 4 \mathrm{~h}$ after mitochondrial $\mathrm{H}_{2} \mathrm{O}_{2}$ ). This observation might represent an attractive target for redox sensors that could measure when $\mathrm{H}_{2} \mathrm{O}_{2}$ peaks in the cytosol in relation to its peak in mitochondria. The peak of cytoplasmatic $\mathrm{H}_{2} \mathrm{O}_{2}$ at a proper time might be of importance to transmit appropriately timed signals about the redox state of the cell to the canonical TTFL oscillator. It is likely that a stable phase relationship is required between both oscillators for their optimal function. Our model also predicts that the system should be able to oscillate even under conditions of constant mitochondrial $\mathrm{H}_{2} \mathrm{O}_{2}$ production. Such a self-sustained nature of the Prx3 cycle could be easily tested in isolated mitochondria led to respire in a constant environment.

It should be noted that the redox model reproduces the circadian rhythms at the level of mitochondrial membranes. Mitochondria vary in number depending on the cell type. For example, a human liver cell contains 1000-2000 mitochondria, whereas a cardiac myocyte contains 7000-10,000 mitochondria [51]. Although single mitochondria might be competent redox oscillators, it seems plausible that they synchronize their redox circadian cycles to each other, as seen by the clear bands in published western blots of $\mathrm{Prx} 3-\mathrm{SO}_{2} \mathrm{H}$ or Srx [11], in order to transmit the information about the redox state of the cell to the TTFL clock as an ensemble. 


\subsection{Concluding Remarks}

Finally, we close with a short remark about the beauty of simple and generic models. We have elaborated on the basic ingredients that constitute the Prx3/Srx redox oscillator in mammalian mitochondria from adrenal gland, heart, and brown adipose tissue. We have found the core motif that is necessary and sufficient to generate self-sustained rhythms that reproduce previously published experimental data. Our model has been implemented using plausible and simple, yet generic mathematical, representations. This five-variable network might be relevant for other simplified oscillatory systems that follow the same logic of fast (in)activation followed by slow negative feedback, such as the mitotic oscillator involving cyclin and Cdc2 kinase interactions or the $\mathrm{Ca}^{2+}$ oscillations based on $\mathrm{Ca}^{2+}$-induced $\mathrm{Ca}^{2+}$ release [52]. The fact that nature has converged on common mathematical structures underlines the links between similar dynamic phenomena occurring in widely different biological settings. It even constitutes a step forward in the synthetic design of reliable biological clocks $[53,54]$.

\section{Materials and Methods}

All temporal simulations and model analyses have been performed with Python, using the odeint integrator from the scipy module.

Author Contributions: Conceptualization, M.d.O. and H.H.; Data curation, M.d.O. and H.H.; Formal analysis, M.d.O. and H.H.; Funding acquisition, A.K. and H.H.; Investigation, M.d.O. and H.H.; Methodology, M.d.O. and H.H.; Project administration, A.K. and H.H.; Resources, M.d.O. and H.H.; Software, M.d.O. and H.H.; Supervision, A.K. and H.H.; Validation, M.d.O. and H.H.; Visualization, M.d.O. and H.H.; Writing-original draft, M.d.O. and H.H.; Writing-review \& editing, A.K. and H.H.

Funding: This research was supported by grants from the Deutsche Forschungsgemeinschaft (A17 278001972-TRR 186, GRK 1772) and the Integrative Research Institute for the Life Sciences at Humboldt Universität zu Berlin. We acknowledge support from the Open Access Publication Fund of Charité-Universitätsmedizin Berlin. The funders had no role in study design, data collection and analyses, decision to publish or preparation of the manuscript.

Acknowledgments: We are grateful for fruitful discussions with Bharath Ananthasubramaniam and Abhishek Upadhyay. We thank anonymous referees for helpful comments.

Conflicts of Interest: The authors declare no conflict of interest.

\section{Abbreviations}

The following abbreviations are used in this manuscript:

$\begin{array}{ll}A & \text { Active Prx3 (Prx3-SOH) } \\ \text { A } & \text { Activation } \\ \text { Aqp } & \text { Aquaporin } \\ \text { a.u. } & \text { Arbitrary unit } \\ \text { Cys } & \text { Cysteine } \\ \text { d } & \text { Day } \\ \mathrm{D}_{1} & \text { Danger } 1 \text { (mitochondrial } \mathrm{H}_{2} \mathrm{O}_{2} \text { ) } \\ \mathrm{D}_{2} & \text { Danger 2 (cytosolic } \mathrm{H}_{2} \mathrm{O}_{2} \text { ) } \\ \mathrm{h} & \text { Hour } \\ \mathrm{H}_{2} \mathrm{O} & \text { Water } \\ \mathrm{H}_{2} \mathrm{O}_{2} & \text { Hydrogen peroxide } \\ \mathrm{I} & \text { Inactive Prx3 (Prx3-SO } \mathrm{H}_{2} \text { ) } \\ \mathrm{I} / \mathrm{L} & \text { Inactivation-Leakage } \\ \mathrm{MAPK} & \text { Mitogen-activated protein kinase } \\ \mathrm{ODE} & \text { Ordinary differential equation } \\ \text { Prx } & \text { Peroxiredoxin }\end{array}$


$R \quad$ Rescuer (Srx)

ROS Reactive oxygen species

Srx Sulfiredoxin

Trx Thioredoxin

TTFL Transcription-translation feedback loop

\section{Appendix A. Detailed Model of Redox Oscillations}

We develop a deterministic model that contains all biochemical species from the Prx3/Srx oscillating system shown in Figure 1B [11]. A scheme of the model and its equations are shown in Figure A1A,B. Production and degradation terms are modeled assuming mass action kinetics. The total Prx3 pool $\left(\mathrm{SH}+\mathrm{SOH}+\mathrm{SO}_{2} \mathrm{H}+\mathrm{SS}\right.$ in the model) and the production of $\mathrm{H}_{2} \mathrm{O}_{2}\left(k_{0}\right.$ in the model) are assumed to be constant over time.

A

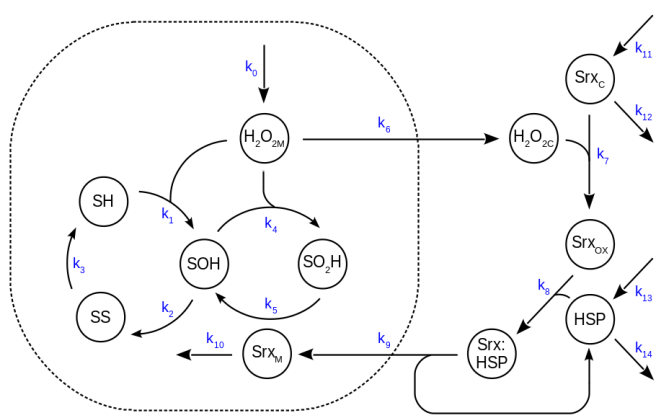

\section{C}

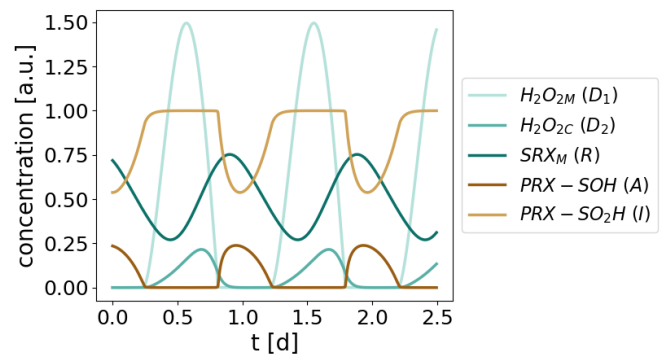

B

$$
\begin{aligned}
& \frac{d \mathrm{H}_{2} \mathrm{O}_{2 M}}{d t}=k_{0}-k_{1} \cdot S H \cdot \mathrm{H}_{2} \mathrm{O}_{2 M}-k_{4} \cdot \mathrm{H}_{2} \mathrm{O}_{2 M} \cdot S O H-k_{6} \cdot \mathrm{H}_{2} \mathrm{O}_{2 M}, \\
& \frac{d \mathrm{H}_{2} \mathrm{O}_{2 \mathrm{C}}}{d t}=k_{6} \cdot \mathrm{H}_{2} \mathrm{O}_{2 M}-k_{7} \cdot S r x_{C} \cdot \mathrm{H}_{2} \mathrm{O}_{2 \mathrm{C}} \\
& \frac{d S r x_{C}}{d t}=k_{11}-k_{7} \cdot S r x_{C} \cdot H_{2} \mathrm{O}_{2 C}-k_{12} \cdot S r x_{C} \text {, } \\
& \frac{d S r x_{O X}}{d t}=k_{7} \cdot S r x_{C} \cdot H_{2} O_{2 C}-k_{8} \cdot S r x_{O X} \cdot H S P, \\
& \frac{d H S P}{d t}=k_{13}+k_{9} \cdot \operatorname{SrxHSP}-k_{14} \cdot H S P-k_{8} \cdot S r x_{O X} \cdot H S P, \\
& \frac{d S r x H S P}{d t}=k_{8} \cdot S r x_{O X} \cdot H S P-k_{9} \cdot S r x H S P, \\
& \frac{d S r x_{M}}{d t}=k_{9} \cdot \operatorname{SrxHSP}-k_{10} \cdot S r x_{M}, \\
& \frac{d S H}{d t}=k_{3} \cdot S S-k_{1} \cdot S H \cdot H_{2} O_{2 M} \\
& \frac{d S O H}{d t}=k_{1} \cdot S H \cdot H_{2} \mathrm{O}_{2 M}+k_{5} \cdot \mathrm{SO}_{2} H \cdot S r x_{M}-k_{2} \cdot S O H-k_{4} \cdot \mathrm{H}_{2} \mathrm{O}_{2 M} \cdot S O H, \\
& \frac{d \mathrm{SO}_{2} \mathrm{H}}{d t}=k_{4} \cdot \mathrm{H}_{2} \mathrm{O}_{2 \mathrm{M}} \cdot \mathrm{SOH}-k_{5} \cdot \mathrm{SO}_{2} \mathrm{H} \cdot \mathrm{Sr} x_{M} \text {, } \\
& S S=1-S H-S O H-S_{2} H .
\end{aligned}
$$

Figure A1. Detailed 10-ordinary differential equation (ODE) model for circadian redox oscillations. (A) Scheme of the biochemical species identified in the mitochondrial Prx3-SO ${ }_{2} \mathrm{H} / \mathrm{Srx}$ circadian oscillating system. (B) Equations of the model. (C) Limit cycle oscillations obtained by numerical integration of the equations shown in (B) for the following parameter values (a.u.): $k_{0}=1, k_{1}=10^{7}, k_{2}=1, k_{3}=1, k_{4}=$ $10^{4}, k_{5}=2, k_{6}=0.2, k_{7}=2, k_{8}=0.5, k_{9}=0.2, k_{10}=0.2, k_{11}=0.2, k_{12}=0.1, k_{13}=0.2, k_{14}=0.1$. The period of oscillation is $23.5 \mathrm{~h}$; the phase shift between $\operatorname{Prx} 3-\mathrm{SO}_{2} \mathrm{H}$ and mitochondrial $\mathrm{Srx}$ is $7.3 \mathrm{~h}$. 
Applying the two ingredients that we identify as design principles of the oscillator, namely fast $\mathrm{SOH}$ inactivation followed by slow $\mathrm{H}_{2} \mathrm{O}_{2 M}-\mathrm{H}_{2} \mathrm{O}_{2} \mathrm{C}-\mathrm{Sr} x_{\mathrm{OX}}-\mathrm{Sr} x \mathrm{Hsp}-\mathrm{Srx}_{M}$ feedback, we obtain oscillations in all 11 variables. The oscillations of the 5 core variables that comprise the minimal oscillator are shown in Figure A1C. The resulting period is $23.5 \mathrm{~h}$ and the phase difference between $\mathrm{Prx} 3-\mathrm{SO}_{2} \mathrm{H}$ and mitochondrial $\mathrm{Srx}$ is $7.3 \mathrm{~h}$. These simulations support the robustness of the minimal model, since applying its design principles into a larger model also generates oscillations with similar characteristics.

Parameters are chosen according to the constraints that we use to infer the parameter values from the minimal model (Table 1). Degradation and translocation rates are kept in the order of magnitude of their corresponding parameters on the minimal model $(d, e, q)$. We set $k_{7}$ (the rate of oxidation of cytosolic Srx that results in an intermolecular bridge with Hsp) to 2, following previous results, which have estimated that Prxs react 1000-10,000 times faster with $\mathrm{H}_{2} \mathrm{O}_{2}$ than other reduced cellular thiols [18]. Biochemical assays have determined the rate constants for Prx3-SH oxidation to sulfenic acid Prx3-SOH ( $k_{1}$ in the detailed model) and hyperoxidation to $\operatorname{Prx} 3-\mathrm{SO}_{2} \mathrm{H}\left(k_{4}\right.$ in the detailed model) to be in the order of $10^{7} \mathrm{M}^{-1} \mathrm{~s}^{-1}$ and $10^{4} \mathrm{M}^{-1} \mathrm{~s}^{-1}$, respectively [18]. We observe that the amplitude of Prx3- $\mathrm{SO}_{2} \mathrm{H}$ and mitochondrial Srx oscillations increases as $k_{1}$ is increased, a result that reproduces the details from published western blot data. Kil and colleagues have shown in [11] intense bands for both Prx3- $\mathrm{SO}_{2} \mathrm{H}$ and mitochondrial $\mathrm{Srx}$ at their peak times and no bands at their troughs, implying that the oscillation amplitude is large.

\section{Appendix B. Model Simplification}

The minimal redox oscillator model used in this paper (Figure 2) is a condensed representation of the complex biochemistry of the Prx3/Srx oscillating system in mitochondria from adrenal gland, heart, and brown adipose tissue (Figure 1B). Whereas the detailed model contains all 11 variables from Figure 1B (Appendix A), the minimal model is a relatively small network with only 5 variables. Because the detailed model contains 15 parameters, most of which are unknown, obtaining oscillations is challenging. For this reason, the 10-ODE detailed model is simplified to the 6-ODE model shown in Figure A2. Apart from the 5 variables from the minimal model, $S$ represents cytosolic $\operatorname{Srx}, A_{1}$ represents the Prx3 in its reduced thiol form (Prx3-SH), and $A_{2}$ represents the sulfenic acid Prx3-SOH. Again, mass action kinetics is used to model production and degradation terms and we assume constant mitochondrial $\mathrm{H}_{2} \mathrm{O}_{2}$ production $p$ as well as constant Prx3 pool $\left(A_{1}+A_{2}+I\right)$ over time.

We find oscillations for the parameter set shown in the caption of Figure A2. To gain insight into the design principles of the Prx3/Srx oscillator and in line with previous theoretical studies [14], we systematically clamp all seven variables. To clamp a variable or a process means to set it to its mean (constant) value, trying to resemble conditions of constitutive expression from the wet lab. This strategy, instead of simply removing a variable, allows us to compare the effect of rhythmic versus basal regulation. Thus, if a state variable is fixed at its mean level (i.e., clamped) and the network remains rhythmic, this means that the clamped variable is not required for the generation of oscillations. It might play a role in regulating the oscillation period or amplitude, but it is not necessary to obtain self-sustained oscillations. By systematically clamping all 7 variables we find that neither $A_{1}$ nor $S$ are necessary for the generation of self-sustained oscillations and thus the 6-ODE model from Figure A2 is simplified to the model shown in Figure A3A. This model version contains the 5 core variables from the minimal model described by 4 ODEs, 6 parameters, and 2 bilinear reactions (equations are shown in Figure A3B). It oscillates with a $24.5 \mathrm{~h}$ period and the phase difference between $\mathrm{Prx}_{3}-\mathrm{SO}_{2} \mathrm{H}$ and mitochondrial Srx is $8.8 \mathrm{~h}$ (Figure $\mathrm{A} 3 \mathrm{C}$ ), as expected. 
A

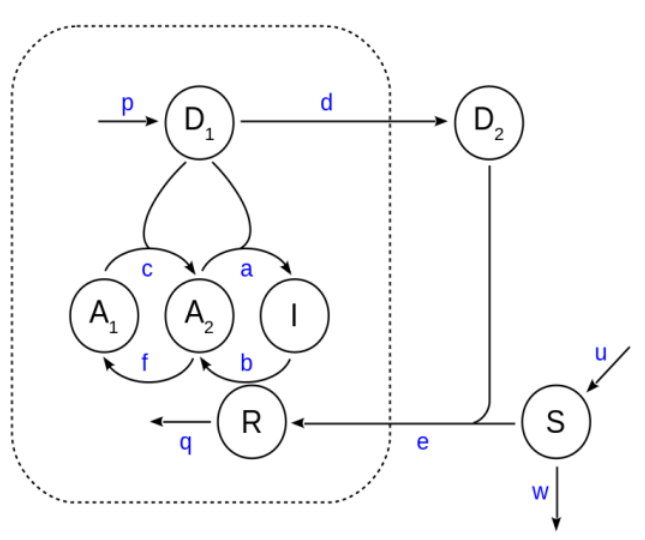

C

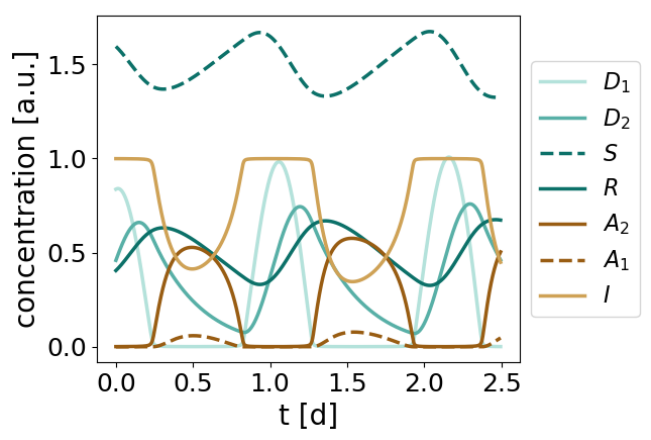

B

$$
\begin{aligned}
\frac{d D_{1}}{d t} & =p-c A_{1} D_{1}-a A_{2} D_{1}-d D_{1} \\
\frac{d D_{2}}{d t} & =d D_{1}-e S D_{2}, \\
\frac{d S}{d t} & =u-e S D_{2}-w S, \\
\frac{d R}{d t} & =e S D_{2}-q R \\
\frac{d A_{2}}{d t} & =c A_{1} D_{1}+b I R-a A_{2} D_{1}-f A_{2}, \\
\frac{d I}{d t} & =a A_{2} D_{1}-b I R \\
A_{1} & =1-A_{2}-I .
\end{aligned}
$$

Figure A2. A 6-ODE model for circadian redox oscillations. (A) The 10-ODE detailed model is simplified to the 7-variable model shown in this figure. $A_{1}$ represents Prx3-SH; $A_{2}$, Prx3-SOH; $I$, Prx3-SO $\mathrm{SO}_{2} \mathrm{H} ; D_{1}$, mitochondrial $\mathrm{H}_{2} \mathrm{O}_{2} ; D_{2}$, cytosolic $\mathrm{H}_{2} \mathrm{O}_{2} ; S$, cytosolic Srx; and $R$, mitochondrial Srx. (B) Equations of the 7-variable model. We assume constant $A_{1}+A_{2}+I$ over time and thus the number of ODEs is reduced to 6 . The dynamics of $A_{1}$ are described by a mass conservation law. (C) Limit cycle oscillations obtained by numerical integration of the equations shown in (B) for the following parameter values (a.u.): $a=1000, b=2, c=10000, d=u=0.2, e=q=w=0.1, f=p=1$. The period of oscillation is $25.3 \mathrm{~h}$; the phase shift between $I$ and $R$ is $8.3 \mathrm{~h}$.

A

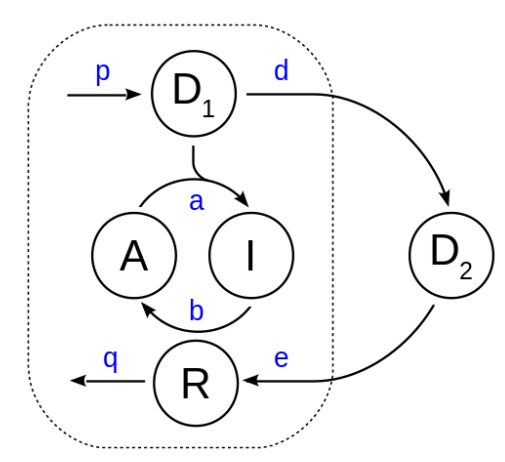

B

$$
\begin{aligned}
\frac{d D_{1}}{d t} & =p-a A D_{1}-d D_{1}, \\
\frac{d D_{2}}{d t} & =d D_{1}-e D_{2}, \\
\frac{d R}{d t} & =e D_{2}-q R \\
\frac{d A}{d t} & =b I R-a A D_{1} \\
I & =1-A .
\end{aligned}
$$

Figure A3. Cont. 
C

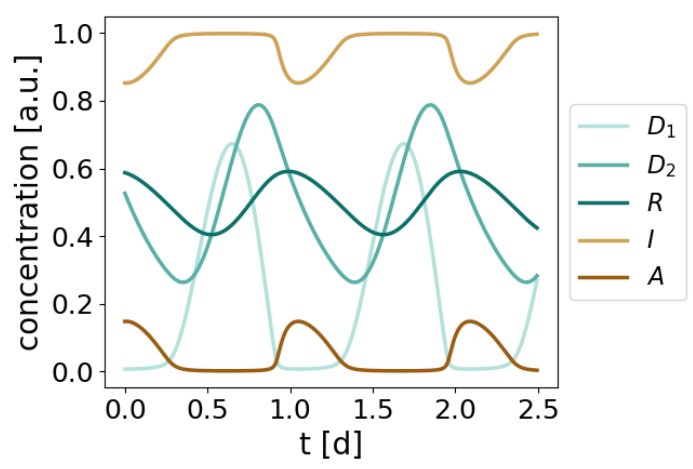

D

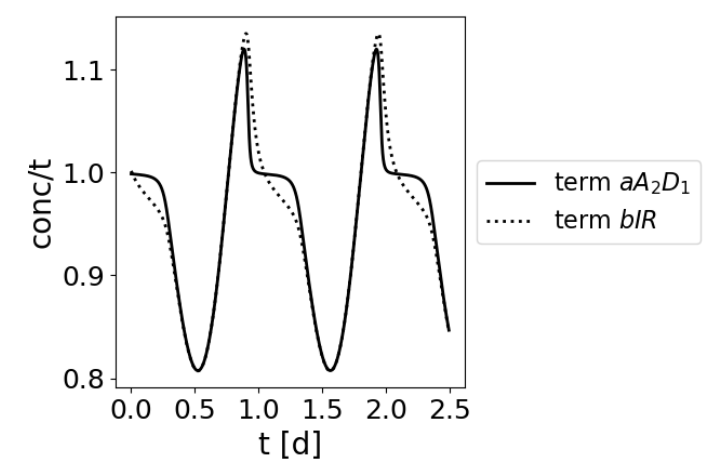

Figure A3. Reduced 4-ODE model for circadian redox oscillations. (A) The 6-ODE model is simplified to the 5-variable model shown in this figure. $A$ represents Prx3-SOH; $I$, Prx3-SO ${ }_{2} \mathrm{H} ; D_{1}$, mitochondrial $\mathrm{H}_{2} \mathrm{O}_{2} ; D_{2}$, cytosolic $\mathrm{H}_{2} \mathrm{O}_{2}$; and $R$, mitochondrial Srx. (B) Equations of the 5-variable model. We assume constant $A+I$ over time and thus the number of ODEs is reduced to 4 , with the dynamics of $I$ being described by a mass conservation law. (C) Limit cycle oscillations obtained by numerical integration of the equations shown in (B) for the following parameter values (a.u.): $a=1000, b=2$, $c=10,000, d=0.2, e=q=0.1, p=1$. The period of oscillation is $24.5 \mathrm{~h}$; the phase shift between $I$ and $R$ is $8.8 \mathrm{~h}$. (D) Similar evolution of the bilinear terms $b I R$ and $a A D_{1}$ over time for the parameter values in $(C)$, allowing the quasi-steady state state approximation that leads to the simplified model shown in Figure 2B.

Interestingly, and as shown in Figure A3D, we observe that the production of $A$ (defined by the bilinear term $b I R$, Figure A3B) is very similar to its removal (defined by the second bilinear term $a A D_{1}$ ) during the whole simulated time. Therefore, and in order to further simplify the model, we assume $a A D_{1}=b I R$ over time (quasi-steady state assumption). This allows the replacement of the $A$-ODE by the following algebraic equation:

$$
A=\frac{b R}{b R+a D_{1}}
$$

This is the equation in the minimal model described in the main text and shown in Figure 2B. The two bilinear terms, due to the quasi-steady state approximation, are thus coupled and transformed into the only nonlinear term in the minimal model (Figure 2B). The dynamics of the system do not change significantly (compare oscillations from Figures 4 and $A 3 C$ ).

The fact that we can introduce the quasi-steady state approximation on $A$ tells much about the system. In general, the quasi steady state assumption is used when one part of the system reacts much more quickly than another $[15,16]$. The module that reacts faster is often said to have a shorter characteristic timescale or to equilibrate faster than the slower one. In chemical terms, when something equilibrates fast, it can be said that it is in steady state with respect to the slower moving system. The time dependence of the faster reacting module can be simplified, reducing the number of variables that the system has to be solved for. In the context of the Prx3/Srx oscillating system, the quasi-steady state approximation performed on $A$ means that $A$ and $I$ react faster than the rest of the variables, and this can indeed be seen in their sharp changes and in the two switches that occur over time (Figure 5B). 


\section{Appendix C. Bifurcation Analyses}

We vary all model parameters and perform bifurcation analyses to obtain a plausible set of parameters that satisfy the physiological constraints. Bifurcation diagrams for the Srx translocation rate (parameter $e$ ), mitochondrial Srx degradation rate $(q), \operatorname{Prx}_{3}-\mathrm{SO}_{2} \mathrm{H}$ reduction rate by $\mathrm{Srx}(b)$ and mitochondrial $\mathrm{H}_{2} \mathrm{O}_{2}$ production $(p)$ are shown in Figure A4. A note on units: the first order translocation and degradation rates $e$ and $q$ have units of $\mathrm{h}^{-1}$; the second order reduction rate $b$ needs inverse units of time $\left(\mathrm{h}^{-1}\right)$ and inverse units of concentration (arbitrary) and $D_{1}$ production rate $p$ has units of concentration (arbitrary) divided by time (h).

A

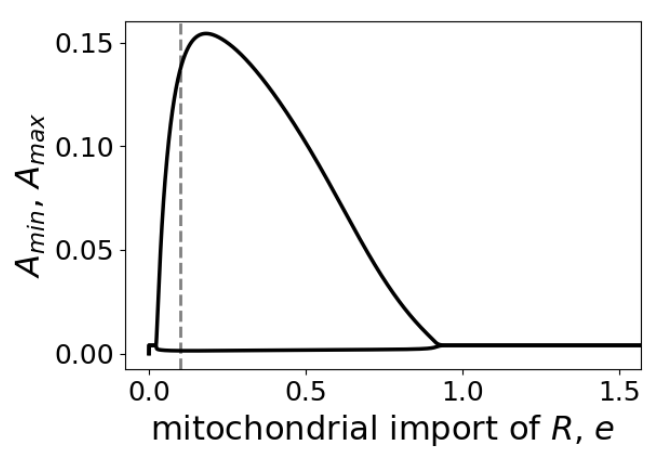

C

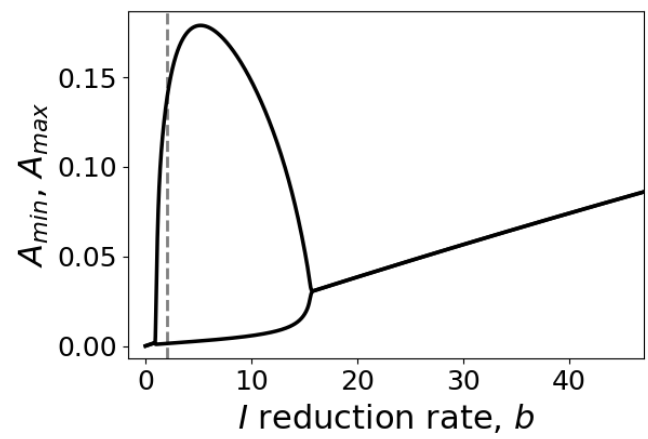

B

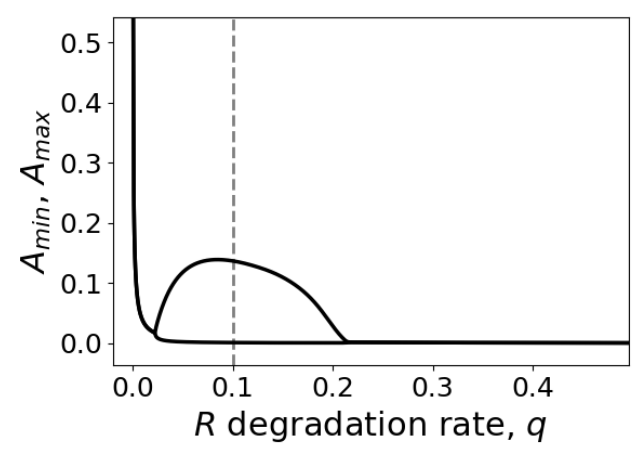

D

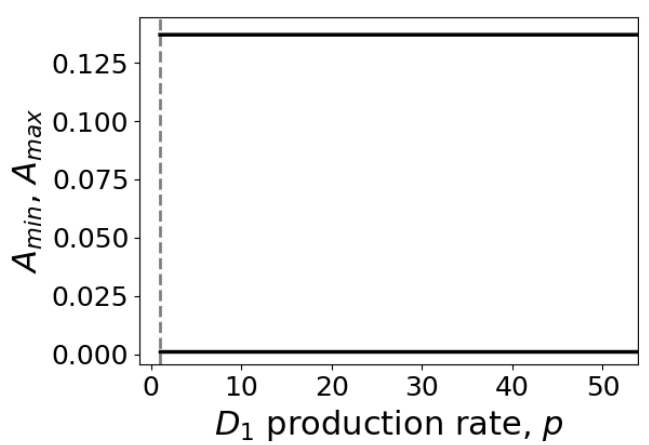

Figure A4. Bifurcation diagrams as a function of the model parameters $e(\mathbf{A}), q(\mathbf{B}), b(\mathbf{C})$, and $p$ (D). At $e=0.03, q=0.025$, and $b=1$ self-sustained oscillations emerge. The system oscillates for any positive value of $p$. $A_{\min }$ and $A_{\max }$ represent the minimum and maximum values of $A$ in the oscillatory regime. The curves are obtained for the default parameter set shown in the caption of Figure 4, by numerical integration of the model equations given in Figure 2B. The dashed gray lines refer to the default parameter values.

\section{Appendix D. Period Sensitivity Analyses}

We also analyze how sensitive the behavior of the redox oscillator model is towards parameter changes. We increase and decrease all model parameters by $10 \%$ and quantify the effect of such change on the oscillation period. The results are shown in Figure A5. As expected [30,31], translocation and degradation rates $d, e$, and $q$ control the period most strongly, but interestingly also the reactivation kinetics represented by $b$ has some effects on the period. 


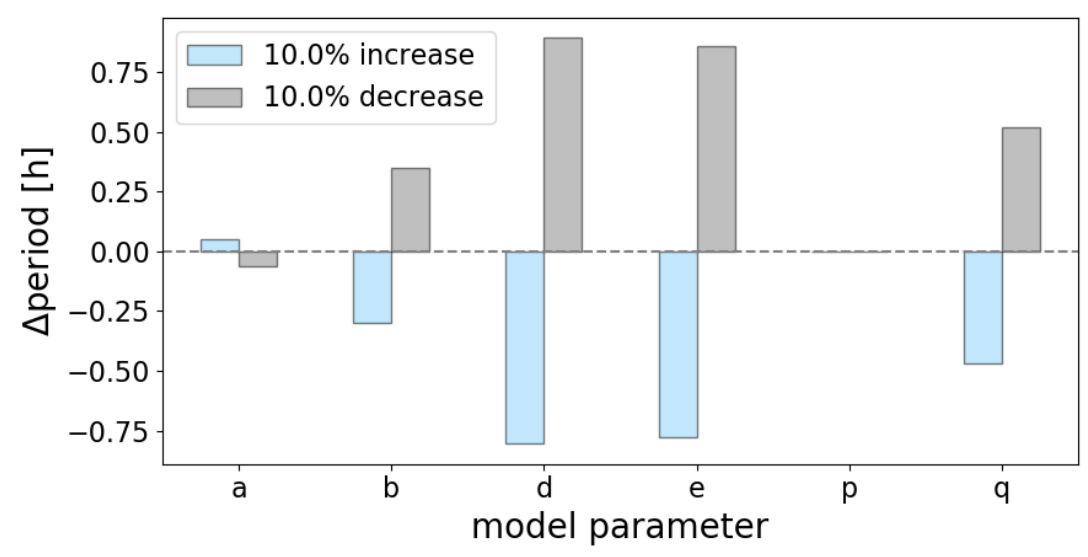

Figure A5. Period sensitivity analysis as a function of a 10\% increase (blue) or $10 \%$ decrease (gray) of the default parameter value shown in the caption of Figure 4 . $\Delta$ period $[\mathrm{h}]$ represents the difference between the period calculated from the new parameter set and the period from the default parameter set. Period values are obtained for each parameter set by numerical integration of the model equations given in Figure 2B.

\section{References}

1. Lowrey, P.L.; Takahashi, J.S. Mammalian circadian biology: Elucidating genome-wide levels of temporal organization. Annu. Rev. Genom. Hum. Genet. 2004, 5, 407-441. [CrossRef] [PubMed]

2. Reppert, S.M.; Weaver, D.R. Coordination of circadian timing in mammals. Nature 2002, 418, 935-941. [CrossRef]

3. Ouyang, Y.; Andersson, C.R.; Kondo, T.; Golden, S.S.; Johnson, C.H. Resonating circadian clocks enhance fitness in cyanobacteria. Proc. Natl. Acad. Sci. USA 1998, 95, 8660-8664. [CrossRef]

4. Hardin, P.E.; Hall, J.C.; Rosbash, M. Feedback of the Drosophila period gene product on circadian cycling of its messenger RNA levels. Nature 1990, 343, 536-540. [CrossRef]

5. Brown, S.A.; Azzi, A. Peripheral circadian oscillators in mammals. In Circadian Clocks; Kramer, A.; Merrow, M., Eds.; Springr: Berlin/Heidelberg, Germany, 2013; pp. 335-358.

6. Nakajima, M.; Imai, K.; Ito, H.; Nishiwaki, T.; Murayama, Y.; Iwasaki, H.; Oyama, T.; Kondo, T. Reconstitution of circadian oscillation of cyanobacterial KaiC phosphorylation in vitro. Science 2005, 308, 414-415. [CrossRef]

7. Sweeney, B.M.; Haxo, F.T. Persistence of a photosynthetic rhythm in enucleated Acetabularia. Science 1961, 134, 4674-4677. [CrossRef] [PubMed]

8. O'Neill, J.S.; Reddy, A.B. Circadian clocks in human red blood cells. Nature 2011, 469, 498-503. [CrossRef] [PubMed]

9. Wood, Z.A.; Schröder, E.; Robin Harris, J.; Poole, L.B. Structure, mechanism and regulation of peroxiredoxins. Trends Biochem. Sci. 2003, 28, 32-40. [CrossRef]

10. Edgar, R.S.; Green, E.W.; Zhao, Y.; Van Ooijen, G.; Olmedo, M.; Qin, X.; Xu, Y.; Pan, M.; Valekunja, U.K.; Feeney, K.A.; et al. Peroxiredoxins are conserved markers of circadian rhythms. Nature 2012, 485, 459-464. [CrossRef]

11. Kil, I.S.; Ryu, K.W.; Lee, S.K.; Kim, J.Y.; Chu, S.Y.; Kim, J.H.; Park, S.; Rhee, S.G. Circadian oscillation of sulfiredoxin in the mitochondria. Mol. Cell 2015, 59, 651-663. [CrossRef] [PubMed]

12. Cho, C.S.; Yoon, H.J.; Kim, J.Y.; Woo, H.A.; Rhee, S.G. Circadian rhythm of hyperoxidized peroxiredoxin II is determined by hemoglobin autoxidation and the $20 \mathrm{~S}$ proteasome in red blood cells. Proc. Natl. Acad. Sci. USA 2014, 111, 12043-12048. [CrossRef]

13. Rhee, S.G.; Jeong, W.; Chang, T.S.; Woo, H.A. Sulfiredoxin, the cysteine sulfinic acid reductase specific to 2-Cys peroxiredoxin: Its discovery, mechanism of action, and biological significance. Kidney Int. Suppl. 2007, 72, S3-S8. [CrossRef]

14. Pett, J.P.; Korenčič, A.; Wesener, F.; Kramer, A.; Herzel, H. Feedback loops of the mammalian circadian clock constitute repressilator. PLoS Comput. Biol. 2016, 12, e1005266. [CrossRef] 
15. Flach, E.H.; Schnell, S. Use and abuse of the quasi-steady-state approximation. Syst. Biol. (Stevenage) 2006, 153, 187-91. [CrossRef] [PubMed]

16. Kim, J.K.; Josić, K.; Bennett, M.R. The relationship between stochastic and deterministic quasi-steady state approximations. BMC Syst. Biol. 2015, 9, 87. [CrossRef] [PubMed]

17. Kil, I.S.; Lee, S.K.; Ryu, K.W.; Woo, H.A.; Hu, M.C.; Bae, S.H.; Rhee, S.G. Feedback control of adrenal steroidogenesis via $\mathrm{H}_{2} \mathrm{O}_{2}$-dependent, reversible inactivation of peroxiredoxin III in mitochondria. Mol. Cell 2012, 46, 584-594. [CrossRef] [PubMed]

18. Peskin, A.V.; Dickerhof, N.; Poynton, R.A.; Paton, L.N.; Pace, P.E.; Hampton, M.B.; Winterbourn, C.C. Hyperoxidation of peroxiredoxins 2 and 3. J. Biol. Chem. 2013, 288, 14170-14177. [CrossRef]

19. Roussel, X.; Béchade, G.; Kriznik, A.; Van Dorsselaer, A.; Sanglier-Cianferani, S.; Branlant, G.; Rahuel-Clermont, S. Evidence for the formation of a covalent thiosulfinate intermediate with peroxiredoxin in the catalytic mechanism of sulfiredoxin. J. Biol. Chem. 2008, 283, 22371-22382. [CrossRef] [PubMed]

20. Bienert, G.P.; Schjoerring, J.K.; Jahn, T.P. Membrane transport of hydrogen peroxide. Biochim. Biophys. Acta 2006, 1758, 994-1003. [CrossRef]

21. Verkman, A.S. Aquaporins at a glance. J. Cell Sci. 2011, 124, 2107-2112. [CrossRef]

22. Li, X.; Wang, X.; Yang, Y.; Li, R.; He, Q.; Fang, X.; Luu, D.T.; Maurel, C.; Lin, J. Single-molecule analysis of PIP2;1 dynamics and partitioning reveals multiple modes of Arabidopsis plasma membrane aquaporin regulation. Plant Cell 2011, 23, 3780-3797. [CrossRef] [PubMed]

23. Packer, L.; Cadenas, E. Methods in Enzymology: Hydrogen Peroxide and Cell Signaling, Part B; Academic Press: Cambridge, MA, USA, 2013.

24. Kim, H.; Jung, Y.; Shin, B.S.; Kin, H.; Song, H.; Bae, S.H.; Rhee, S.G.; Jeong, W. Redox regulation of lipopolysaccharide-mediated sulfiredoxin induction, which depends on both AP-1 and Nrf2. J. Biol. Chem. 2010, 285, 34419-34428. [CrossRef] [PubMed]

25. Novák, B.; Tyson, J.J. Design principles of biochemical oscillators. Nat. Rev. Mol. Cell Biol. 2008, 9, 981-991. [CrossRef]

26. Bordyugov, G.; Westermark, P.O.; Korenčič, A.; Bernard, S.; Herzel, H. Mathematical modeling in chronobiology. In Circadian Clocks; Kramer, A.; Merrow, M., Eds.; Springr: Berlin/Heidelberg, Germany, 2013; pp. 45-66.

27. MacDonald, N. Biological Delay Systems: Linear Stability Theory; Cambridge University Press: Cambridge, UK, 1989.

28. Relogio, A.; Westermark, P.O.; Wallach, T.; Schellenberg, K.; Kramer, A.; Herzel, H. Tuning the mammalian circadian clock: Robust synergy of two loops. PLoS Comput. Biol. 2011, 7, e1002309. [CrossRef]

29. Vanselow, K.; Vanselow, J.T.; Westermark, P.O.; Reischl, S.; Maier, B.; Korte, T.; Herrmann, A.; Herzel, H.; Schlosser, A.; Kramer, A. Differential effects of PER2 phosphorylation: Molecular basis for the human familial advanced sleep phase syndrome (FASPS). Genes Dev. 2006, 20, 2660-2672. [CrossRef] [PubMed]

30. Gérard, C.; Gonze, D.; Goldbeter, A. Dependence of the period on the rate of protein degradation in minimal models for circadian oscillations. Philos. Trans. A Math. Phys. Eng. Sci. 2009, 3674, 4665-4683. [CrossRef] [PubMed]

31. Griffith, J.S. Mathematics of cellular control processes. I. Negative feedback to one gene. J. Theor. Biol. 1968, 20, 202-208. [CrossRef]

32. Tyson, J.J.; Chen, K.C.; Novak, B. Sniffers, buzzers, toggles and blinkers: Dynamics of regulatory and signaling pathways in the cell. Curr. Opin. Cell Biol. 2003, 15, 221-231. [CrossRef]

33. Ferrell, J.E.J.; Tsai, T.Y.; Yang, Q. Modeling the cell cycle: Why do certain circuits oscillate? Cell 2011, 144, 874-885. [CrossRef]

34. Blüthgen, N.; Legewie, S.; Herzel, H.; Kholodenko, B. Mechanisms generating ultrasensitivity, bistability, and oscillations in signal transduction. In Introduction to Systems Biology; Choi, S., Ed.; Humana Press: New York, NY, USA, 2007; Chapter 15, pp. 282-299.

35. Gonze, D.; Abou-Jaoudé, W. The Goodwin model: Behind the Hill function. PLoS ONE 2013, 8, e69573. [CrossRef]

36. Kim, J.K. Protein sequestration versus Hill-type repression in circadian clock models. IET Syst. Biol. 2016, 10, 125-135. [CrossRef]

37. Ferrell, J.E.J.; Ha, S. Ultrasensitivity part I: Michaelian responses and zero-order ultrasensitivity. Trends Biochem. Sci. 2014, 39, 496-503. [CrossRef] 
38. Ferrell, J.E.J.; Ha, S. Ultrasensitivity part II: Multisite phosphorylation, stoichiometric inhibitors, and positive feedback. Trends Biochem. Sci. 2014, 39, 556-569. [CrossRef]

39. Ferrell, J.E.J.; Ha, S. Ultrasensitivity part III: Cascades, bistable switches, and oscillators. Trends Biochem. Sci. 2014, 39, 612-618. [CrossRef]

40. Strogatz, S.H. Nonlinear Dynamics and Chaos: With Applications to Physics, Biology, Chemistry and Engineering; Westview Press: Cambridge, MA, USA, 2000.

41. Ananthasubramaniam, B.; Herzel, H. Positive feedback promotes oscillations in negative feedback loops. PLoS ONE 2014, 9, e104761. [CrossRef] [PubMed]

42. Santos, S.D.M.; Ferrell, J.E.J. On the cell cycle and its switches. Nature 2008, 454, 288-289. [CrossRef]

43. Ferrell, J.E.J.; Pomerening, J.R.; Kim, S.Y.; Trunnell, N.B.; Xiong, W.; Huang, C.Y.; Machleder, E.M. Simple, realistic models of complex biological processes: Positive feedback and bistability in a cell fate switch and a cell cycle oscillator. FEBS Lett. 2009, 583, 3999-4005. [CrossRef]

44. Zhang, E.E.; Liu, A.C.; Hirota, T.; Miraglia, L.J.; Welch, G.; Pongsawakul, P.Y.; Liu, X.; Atwood, A.; Huss, J.W.; Janes, J.; et al. A genome-wide RNAi screen for modifiers of the circadian clock in human cells. Cell 2009, 139, 199-210. [CrossRef] [PubMed]

45. Buijs, R.M.; Kalsbeek, A. Hypothalamic integration of central and peripheral clocks. Nat. Rev. Neurosci. 2001, 2, 521-526. [CrossRef]

46. Oster, H.; Damerow, S.; Kiessling, S.; Jakubcakova, V.; Abraham, D.; Tian, J.; Hoffmann, M.W.; Eichele, G. The circadian rhythm of glucocorticoids is regulated by a gating mechanism residing in the adrenal cortical clock. Cell Metab. 2006, 4, 163-173. [CrossRef] [PubMed]

47. Peek, C.B.; Affinati, A.H.; Ramsey, K.M.; Kuo, H.Y.; Yu, W.; Sena, L.A.; Ilkayeva, O.; Marcheva, B.; Kobayashi, Y.; Omura, C.; et al. Circadian clock NAD+ cycle drives mitochondrial oxidative metabolism in mice. Science 2013, 342, 1243417. [CrossRef]

48. Schmalen, R.; Reischl, S.; Wallach, T.; Klemz, R.; Grudziecki, A.; Prabu, J.R.; Benda, C.; Kramer, A.; Wolf, E. Interaction of circadian clock proteins CRY1 and PER2 is modulated by zinc binding and disulfide bond formation. Cell 2014, 157, 1203-1215. [CrossRef] [PubMed]

49. Gupta, N.; Ragsdale, S.W. Thiol-disulfide redox dependence of heme binding and heme ligand switching in nuclear hormone receptor Rev-erb $\beta$. J. Biol. Chem. 2010, 286, 4392-4403. [CrossRef]

50. Rutter, J.; Reick, M.; Wu, L.C.; McKnight, S.L. Regulation of clock and NPAS2 DNA binding by the redox state of NAD cofactors. Science 2001, 293, 510-514. [CrossRef]

51. Nivala, M.; Korge, P.; Nivala, M.; Weiss, J.N.; Qu, Z. Linking flickering to waves and whole-cell oscillations in a mitochondrial network model. Biophys. J. 2011, 101, 2102-2111. [CrossRef] [PubMed]

52. Goldbeter, A. Biochemical Oscillations and Cellular Rhythms. The Molecular Bases of Periodic and Chaotic Behavior; Cambridge University Press: Cambridge, UK, 1996.

53. Elowitz, M.B.; Leibler, S. A synthetic oscillatory network of transcriptional regulators. Nature 2000, 403, 335-338. [CrossRef] [PubMed]

54. Atkinson, M.R.; Savageau, M.A.; Myers, J.T.; Ninfa, A.J. Development of genetic circuitry exhibiting toggle switch or oscillatory behavior in Escherichia coli. Cell 2003, 113, 597-607. [CrossRef]

(C) 2019 by the authors. Licensee MDPI, Basel, Switzerland. This article is an open access article distributed under the terms and conditions of the Creative Commons Attribution (CC BY) license (http://creativecommons.org/licenses/by/4.0/). 